\title{
WestVirginiaUniversity
}

THE RESEARCH REPOSITORY @ WVU

Graduate Theses, Dissertations, and Problem Reports

2007

\section{Accessibility of WVU websites for individuals with vision impairments}

Sarah Jacobin

West Virginia University

Follow this and additional works at: https://researchrepository.wvu.edu/etd

\section{Recommended Citation}

Jacobin, Sarah, "Accessibility of WVU websites for individuals with vision impairments" (2007). Graduate Theses, Dissertations, and Problem Reports. 1856.

https://researchrepository.wvu.edu/etd/1856

This Thesis is protected by copyright and/or related rights. It has been brought to you by the The Research Repository @ WVU with permission from the rights-holder(s). You are free to use this Thesis in any way that is permitted by the copyright and related rights legislation that applies to your use. For other uses you must obtain permission from the rights-holder(s) directly, unless additional rights are indicated by a Creative Commons license in the record and/ or on the work itself. This Thesis has been accepted for inclusion in WVU Graduate Theses, Dissertations, and Problem Reports collection by an authorized administrator of The Research Repository @ WVU. For more information, please contact researchrepository@mail.wvu.edu. 
Accessibility of WVU Websites for Individuals with Vision Impairments

Sarah Jacobin

Thesis submitted to the Perley Isaac Reed School of journalism at West Virginia University in partial fulfillment of the requirements for the degree of

Master of Science

in

Journalism

Approved by

Ralph Hanson, Ph.D., Chair Joel William Beeson, M.A.J. John Temple, M.F.A.

A. Diane Williams, M.S.W.

Perley Isaac Reed School of Journalism

Morgantown, West Virginia

2007

Keywords: Accessible, Disability, Visual, Vision, Website Accessibility, Assistive Technology, Screen Reader, Narrator, Website Design

Copyright 2007 Sarah Jacobin 


\begin{abstract}
Accessibility of WVU Websites for Individuals with Visual Impairments
\end{abstract}

Sarah Jacobin

Recently, several major corporations have been sued because their websites are inaccessible to individuals with disabilities. For a website to be accessible, people with disabilities should be able to navigate and interact with the site. Individuals who are blind or have vision impairments have difficulty accessing websites because they commonly use assistive technology to interpret content. This study is the first comprehensive study assessing the accessibility of WVU websites for individuals with disabilities, specifically individuals with visual impairments and comparing those results to those of two comparable universities in other areas of the country. Compliance with specifications of website accessibility is an important goal for any state university and is also required by law. WVU websites and those of other universities' were measured using the WAB Score. The WAB Score consists of 25 checkpoints that are based on WCAG accessibility standards. The higher the WAB Score, the more accessibility barriers that exist. A score of zero indicates that the website does not have any violations while a WAB Score of 5.5 serves as the threshold between accessible and inaccessible. WVU websites had a mean WAB Score that was accessible by .07 points, but specific sites and departments had severely inaccessible websites. The websites at WVU that were particularly inaccessible to individuals with visual impairments consisted of flashy design elements and graphics. The high and low priority violations that were found on WVU websites are mostly items that would take little time to correct. All universities should use this process to assess their current level of accessibility and locate the specific areas of their websites that are particularly inaccessible. Future research should take a qualitative approach and explore the knowledge web designers have about accessibility through one on one interviews and surveys. A future study might also concentrate on the idea of a link between "catchy", complex website design and inaccessibility. 


\section{DEDICATION}

The author wishes to dedicate this research to the late Ken Ervin, a WVU Alumnus and a great disability advocate in West Virginia and nationwide. A man that would be proud that this study will shed light on the difficulties in today's world for individuals with disabilities. 


\section{ACKNOWLEDGEMENTS}

The author wishes to thank Bambang Parmanto, Ph.D at the University of Pittsburgh for allowing the use of his WebCrawler WAB Score calculating software, Kelvin (version 2) and Ralph Hanson, Ph.D. for his guidance and helpfulness with this research.

The author would also like to thank every committee member for their input and ability to work together to effectively merge two disciplines. 


\section{TABLE OF CONTENTS}

Chapter 1: Introduction and Problem............................................................

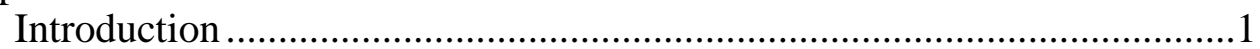

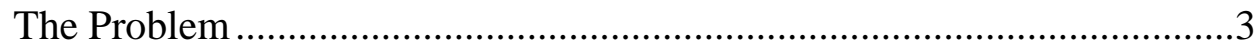

Chapter 2: Purpose and Review of the Literature ..........................................4

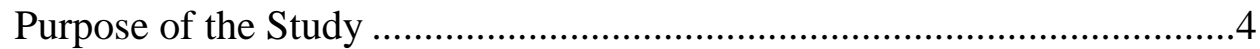

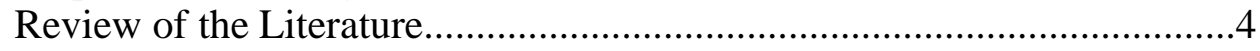

Chapter 3: Methodology, Instrumentation and Analysis ................................

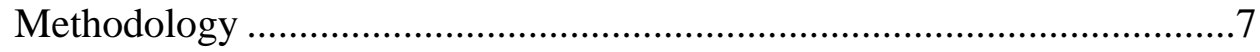

Research Questions ................................................................................

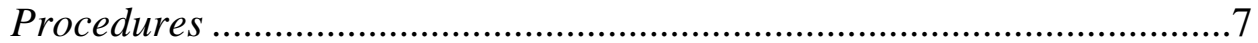

Population and Sample .................................................................. 7

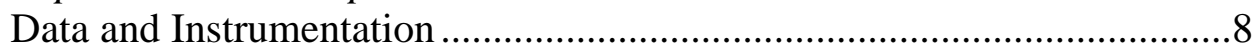

Mode of Analysis ............................................................................. 9

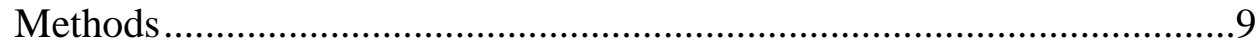

Chapter 4: Overall Results and Comparisons .................................................12

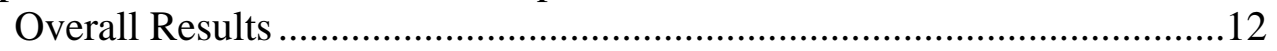

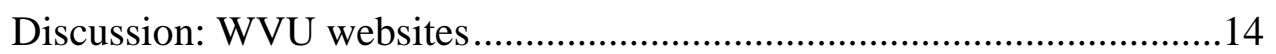

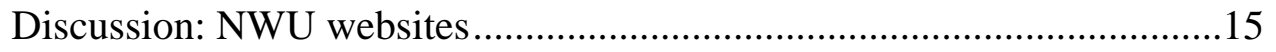

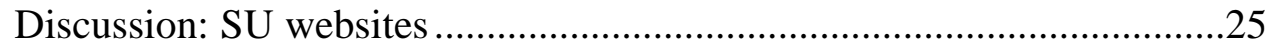

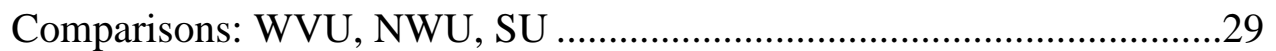

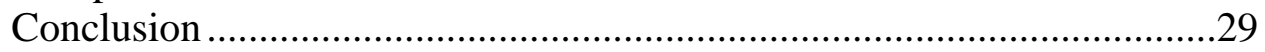

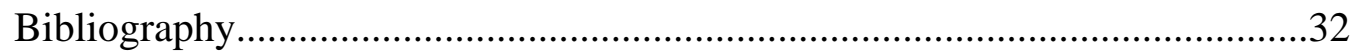

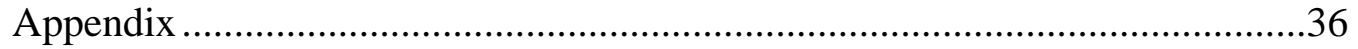

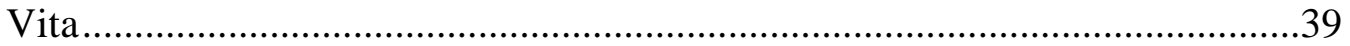




\section{LIST OF FIGURES}

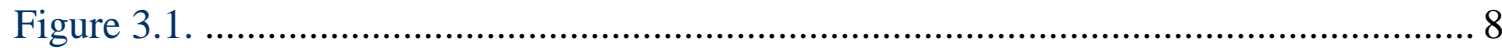

Figures 4.1 and 4.2 .............................................. 15 


\section{LIST OF TABLES}

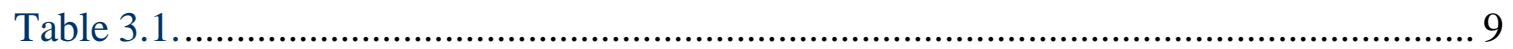

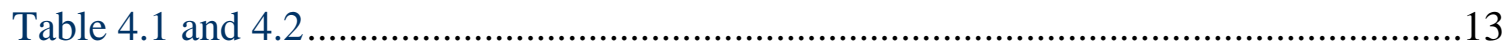

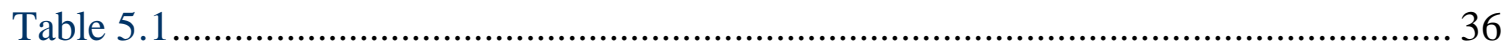




\section{LIST OF IMAGES}

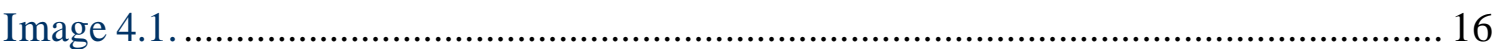

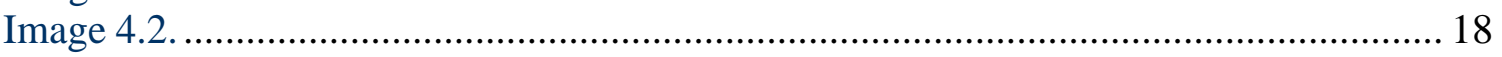

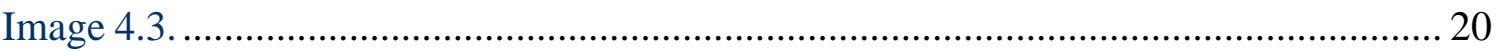

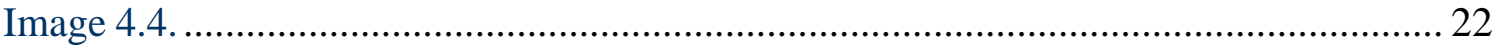

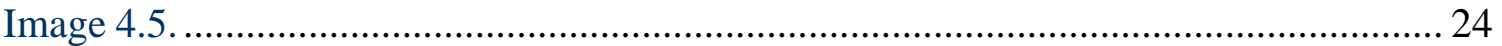

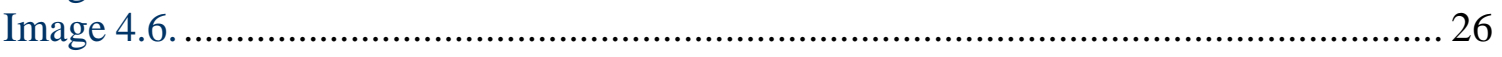

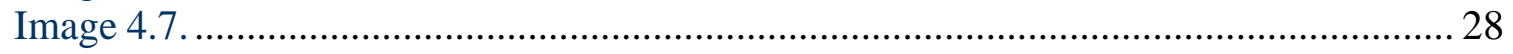




\section{Chapter 1: Introduction and Problem}

\section{$\underline{\text { Introduction }}$}

In 2003, New York State Attorney General, Elliot Spitzer, filed suit under the Americans with Disabilities Act against Priceline.com and Ramada.com for failing to make their websites accessible (WEBAIM 2007). The companies reportedly settled and made changes to the websites, but the case brought attention to the issue of website accessibility and prompted other companies and organizations to improve the accessibility of their websites. However, inaccessibility is still a major issue. Within the past six months, the National Foundation of the Blind began pursuing a lawsuit against Target.com for website inaccessibility to people who have visual impairments (Sliwa 2006).

Web accessibility means that "people with disabilities can perceive, understand, navigate, and interact with the Web and that they can contribute to the Web" (W3C 2007). The issue appeared to gain popularity after Congress amended the Rehabilitation Act in 1998 to require Federal agencies to make their electronic and information technology accessible to people with disabilities (Section 508 2007). This part of the Rehabilitation Act, known as Section 508, even though targeted toward federally funded entities, soon served as an unwritten guideline for other agencies and businesses, as seen in the lawsuits filed in New York and elsewhere (Sliwa 2006).

Several studies conducted after the enactment of Section 508 found that individuals who are blind or have visual impairments have the most difficult time accessing websites compared to individuals with other disabilities (Federici 2005). Individuals who are blind or visually impaired can have a difficult time surfing the internet because they commonly use assistive technology to interpret website content. Unfortunately, as in the case of Target, some websites are not designed to allow for the use of assistive technology (Sliwa 2006).

Assistive or adaptive technology commonly refers to "... products, devices or equipment, whether acquired commercially, modified or customized, that are used to maintain, increase or improve the functional capabilities of individuals with 
disabilities"(Assistive Technology Act of 1998). In the context of on-line education, assistive technology refers to hardware and software technologies that enable people with disabilities to use computers more effectively (National Center 2007). Screen readers, refreshable braille displays and screen magnifiers are all common assistive technology devices used by individuals who are blind or have vision impairments.

According to the World Wide Web Consortium (W3C 2007), there are two key aspects of accessible design, graceful transformation and understandable, navigable content (W3C: "Web" 1999) The W3C is the international oversight body for protocols and operations of the internet that released the Web Content Accessibility Guidelines or WCAG 1.0 in 1999 (An updated version was in the comment stage during the writing of this paper (W3C: "Web" 1999). Using WCAG, website developers can design websites to be accessed more easily by individuals using screen readers and other assistive technology.

WCAG show that simple design methods can be utilized by web developers to ensure a website does not contain accessibility barriers. The use of system standard onscreen controls and the practice of defining tools in toolbars and menus are just a couple of basic, but important accessibility guidelines. (W3C:"Objects" 1999). WCAG also takes into account the use of software to enlarge the screen (screen magnifier), change contrast and enlarge text by individuals with low vision (W3C:"Web" 1999). According to WCAG, these technologies are much easier to use when the contrast of text and background on web pages ensures that text is easily discernable and patterned and busy backgrounds are avoided (W3C:"Web" 1999). A majority of the WCAG deals with vision impairments because of the high rate of accessibility barriers for these users (W3C: "Web" 1999).

The high inaccessibility of the internet for individuals with vision impairments is significant considering that there are approximately 10 million individuals in the United States who are blind or have low vision (AFB 2007). Of these individuals, more are learning to use the computer to meet their needs, especially to aid them in higher education. A survey of first time, full-time freshmen attending four-year institutions found that out of all students reporting the presence of a disability, 16 percent identified themselves as partially sighted or blind. (HEATH 2001). 


\section{The Problem}

Individuals who are blind or have vision impairments are guaranteed access to all post-secondary programs and services under Section 504 of the Rehabilitation Act and the Americans with Disabilities Act (WEBAIM 2007). Post-secondary institutions are continuously incorporating new services through course management systems (CMSs) and online courses for distance learning. Post-secondary programs and services such as these should be easily accessible to students with visual impairments.

Accessibility studies conducted on websites, including those of postsecondary institutions, from 1998 to the present have found that most are lacking in even the basic standards of accessibility (Klein, Federici, Fujiki etc.). Because of these findings, one must question the accessibility of higher education websites specifically for individuals with visual impairments since they are a population that is considered to have more difficulty accessing online information. If university websites are inaccessible, individuals with visual impairments are not being offered the equal access they are guaranteed by law. For these reasons, it would be beneficial to West Virginia University and students with disabilities who attend and will attend the University, to be aware of the accessibility of the institution's websites. 


\section{Chapter 2: Purpose and Review of the Literature}

\section{Purpose of the Study}

The purpose of this study is to measure West Virginia University's website accessibility for students and users who are blind or visually impaired and compare that measurement to the measurement of other websites of major higher education institutions. The study results would give a quantitative value to the accessibility of WVU websites and allow the comparison of WVU website accessibility scores and the accessibility scores of other websites. The research will serve as a pragmatic evaluation tool and guide for future improvement in website accessibility and could be measured over time to check performance. By assessing the accessibility of online materials now, WVU could avoid legal problems in the future and possibly recruit more students who are blind or have visual impairments.

\section{$\underline{\text { Review of the Literature }}$}

Until recently, accessibility measurement software, BOBBY, based on the WCAG, was the preferred method of measuring website accessibility. Based on the guidelines, the software rates a website as either "approved" or "not approved" (Klein 2003). Several studies on website accessibility have used the objective measurements of BOBBY software. In one study, 157 Iowa high school websites (all websites tested) were not approved by BOBBY (Klein 2003). This high number could demonstrate the inadequacy of the accessibility of educational websites, but it also leads one to question the validity of BOBBY's measurements. Although BOBBY is a tool that can provide an objective accessibility measure, it can only provide researchers with two measurements (Hackett et al. 2005). One "not approved" site may be accessibly very different from another. Using BOBBY, a website with a one accessibility mistake is rated the same as a site with several accessibility flaws.

Due to these issues, Zeng decided to develop a new metric that would be capable of producing a measurement on an accessibility range (2004). He eventually developed the Web Access Barrier Score or WAB Score (Zeng 2004). The WAB Score measures 
web sites on a continuum from perfectly accessible to completely inaccessible. After Zeng's original study, the metric was used with significant and accurate results by Hackett in two separate studies (Hacket et al. 2005 and Hacket and Parmanto 2005). Because the WAB Score was only tested in a few studies by the same authors, I propose using the measurement in my study to further test the metric's ability to effectively and reliably measure web accessibility.

The WAB Score was used specifically to analyze higher education websites (Hackett and Parmanto 2005). However, Hackett's longitudinal study of university websites is the only use of the WAB Score to assess post-secondary education websites (Hackett and Parmanto 2005). The proposed study will be the second such study to use the new metric. In previous studies, higher education website accessibility was testes using the BOBBY measurement. Using BOBBY, an analysis of prominent colleges, universities and online learning institutions from all 50 states found that less than one in four had institutional home pages that would receive BOBBY approval (Walden 2000). The limited measuring capabilities of BOBBY (discussed above) may prove this study inaccurate, but it is worth noting that a similar study (also using BOBBY) conducted one year later gave similar results (Walden 2000).

Not only have studies shown a lack of improvement in website accessibility, but most websites get more inaccessible over time (Hackett et al 2005). From 1997 to 2002 websites got progressively more inaccessible except for US government websites. In fact, the Federal government websites continued to increase in complexity, but remained accessible, according to the WAB Score (Hackett et al. 2005). This study seemed to show that websites could increase in complexity while remaining accessible; a feat that many web developers had claimed was impossible (Hackett et al. 2005).

Despite more complex web design, several studies have concluded that the most common accessibility problem is a very basic design element (Federici, Fujiki, Heim). The lack of alternate or ALT text has been a top accessibility barrier over the years (Federici,Fujiki, Heim). ALT text serves as a description of an image for a website user who may not be able to see the image. It most commonly assists individuals with visual impairments that use screen readers and braille displays to view websites (W3C:"Objects" 1999). The textual definitions that ALT text provides are important 
because they make it easier for assistive technology software to digest and report the image information to a user with vision impairment. 


\section{Chapter 3: Methodology, Instrumentation and Analysis}

\section{Methodology}

\section{Research Questions}

Research Question 1: What is the average WAB Score of WVU websites? And are the websites accessible or inaccessible to students with visual impairments?

Research Question 2: How does the WAB Score of WVU websites compare to the mean WAB Scores of two similar universities?

Research Question 3: Based on the guidelines measured using the WAB Score, what are the most common website accessibility issues among students with vision impairments at these schools?

Research Question 4: What accessibility issues does the WAB Score suggest the websites are lacking in and how can they be improved based upon W3C suggestions?

\section{Procedures}

The most useful method for measuring website accessibility is content analysis. The literature reviewed illustrates that the most encompassing content analysis would utilize the WAB Score. The unit of measure for the content analysis will be the front page and two consecutive links of each website in the sample.

\section{Population and Sample}

Three populations will be represented in this study, a sample of WVU websites and a sample of two selected major research higher education institution websites. This approach will allow comparisons of WVU data with that of the other universities. The Research institutions will only be identified using a regional name. For instance, a university that becomes a part of the sample and is located in the northeast will be referred to as a university in the Northeast instead of the true name of the institution. The limited identification will be adequate because the universities will simply serve as a comparative element within the study. The WVU research sample will be selected by 
visiting the WVU A-Z Site index and choosing the every eighth website. A convenience sample of websites at other institutions will be selected by choosing two state universities that re similar to WVU in regards to academics, physical size and enrollment. The websites of the two institutions will then be selected by a WebCrawler program by entering the root school site address (ex. www.wvu.edu) and then letting the programs measure up to 94 websites that originate from that site.

\section{Data and Instrumentation}

Data will be collected by analyzing the content of websites from the samples listed above. Each front page of the website and two consecutive linked pages will be analyzed using the WAB score (Parmanto and Zeng 2003). A site-wide score will be computed for each website by averaging the WAB score of the three separate web pages. The WAB metric provides a quantitative score on a continuum ranging from perfectly accessible to completely accessible (see figure 3.1 for the WAB formula). Using the WAB score, website scores can be compared to other websites and scores can be evaluated over time. These comparisons are not possible with the commonly used BOBBY accessibility measurement.

The WAB score consists of 25 checkpoints that are based on WCAG accessibility standards. The score itself consists of the number of violations for 25 checkpoints (see Table 3.1). The violations are normalized against the number of possible violations. The 25 checkpoints are divided based on the WCAG rating of priority, but the ratings are in reverse. This means that a priority one violation weighs three times as

$$
\text { WABScore }=\frac{\sum_{p} \sum_{v}\left(\frac{n_{v}}{N_{v}}\right)\left(w_{v}\right)}{N p}
$$

$p:$ Total pages of a website

$v$ : Total violations of a Web page

$n_{v}:$ Number of violations

$N_{v}:$ Number of potential violations

$W v:$ Weight of violations in inverse

proportion to WCAG priority level.

$N p:$ Total number of pages checked much as a priority three violation. The

higher the WAB Score, the more accessibility barriers that exist. A score of zero indicates that the website does not have any violations and should be completely accessible. A WAB Score of 5.5 serves as the threshold between accessible and inaccessible websites (Hackett et al. 2005).

Figure 3.1. The WAB Formula 


\section{$\underline{\text { Mode of Analysis }}$}

Means will be used to obtain basic statistics and Analysis of Variance (ANOVA) procedures will be used to compare mean WAB Scores. If statistical significance is found, Tukey's 'Honestly Significant Different' (HSD) procedures will be used to run comparisons between websites and universities.

\section{Table 3.1. Checkpoints of the WAB score}

\begin{tabular}{|c|c|c|c|c|}
\hline Priority & Checkpoint & Score & & \\
\hline 1 & Provide alternative text for all images & & & \\
\hline 1 & Provide alternative text for each applet & & & \\
\hline 1 & $\begin{array}{l}\text { Provide alternative content for each } \\
\text { object }\end{array}$ & & & \\
\hline 1 & $\begin{array}{l}\text { Provide alternative text for all image- } \\
\text { type buttons in forms }\end{array}$ & & & \\
\hline 1 & $\begin{array}{l}\text { Provide alternative text for all image } \\
\text { map hot-spots (areas) }\end{array}$ & & & \\
\hline 1 & $\begin{array}{l}\text { Each frame must reference an HTML } \\
\text { file }\end{array}$ & & & \\
\hline 1 & Give each frame a title & & & \\
\hline 2 & $\begin{array}{l}\text { Use a public text identifier in a } \\
\text { DOCTYPE statement }\end{array}$ & & & \\
\hline 2 & $\begin{array}{l}\text { Use relative sizing and positioning ( } \\
\text { percent values) rather than absolute } \\
\text { (pixels) }\end{array}$ & & & \\
\hline 2 & Nest Headings Properly & & & \\
\hline 2 & $\begin{array}{l}\text { Provide a NOFRAMES section when } \\
\text { using frames }\end{array}$ & & & \\
\hline 2 & $\begin{array}{l}\text { Avoid blinking text created with the } \\
\text { BLINK element }\end{array}$ & & & \\
\hline 2 & $\begin{array}{l}\text { Avoid scrolling text created with the } \\
\text { MARQUEE element }\end{array}$ & & & \\
\hline 2 & $\begin{array}{l}\text { Do not cause a page to refresh } \\
\text { automatically }\end{array}$ & & & \\
\hline 2 & Don not cause a page to redirect to a & & & \\
\hline
\end{tabular}


new URL

2

2

2

2

3

3

3

3

3

Make sure event handlers do not require

use of a mouse

Explicitly associate form controls and their labels with the LABEL element

Create link phrases that make sense

when read out of context.

Do not use the same link phrase more

than once when the links point to

different URLs

Include a document TITLE

Client-side image map contains a link

not presented elsewhere on the page

Identify the language of the text

Provide a summary of tables

Include default, place-holding

characters in edit boxes and text areas

Separate adjacent links with more than

white space

\section{Methods}

A total of 282 websites were analyzed including 94 WVU websites, 94 websites of a University in the Northwest (NWU) and 94 websites of a University in the South (SU). WVU websites were chosen using the WVU A-Z site index, every eighth website was assessed except for websites that were not directly associated with WVU and those that had bad URLs. NWU and SU were chosen because of their similarities to WVU, including size and enrollment. The websites of these universities were selected by entering the main school's URL into a WebCrawler program that generated a list of all URLs in the same path of the site. Descriptive statistics were calculated for all WAB Scores, each group of the three university's WAB Scores and WAB Scores for each category of WVU websites. All WAB scores were calculated using Kelvin V.2 (Parmanto) and all statistical analyses were conducted using the SPSS 15.0 package. 
Descriptive statistics were generated for the data and a one-way analysis of variance test (ANOVA) was applied to the WAB Scores along with a Tukey post test. 


\section{Chapter 4: Overall Results and Comparisons}

\section{$\underline{\text { Overall Results }}$}

Mean WAB Scores were calculated for each university (See Table 4.1), WVU had the lowest mean WAB score of the three universities $(m=5.43)$, the highest standard deviation $(\mathrm{sd}=2.67)$ and the largest range of WAB Scores $(1-11.95)$. SU had a mean WAB Score similar to WVU $(m=5.63)$ with a lower standard deviation $(\mathrm{sd}=2.03)$. NWU had the most inaccessible mean WAB Score $(m=6.27)$, the lowest standard deviation $(\mathrm{sd}=1.84)$ and a narrow range of scores, with most falling on the inaccessible side of the WAB continuum. ANOVA was computed to compare the mean WAB Scores of the three universities (see Table 4.2)). The test showed that the likelihood of a significant difference between the groups was marginal $(\mathrm{F}=3.725, \mathrm{p}<.025)$. Tukey's HSD was used to further comparisons. The multiple analysis test showed a significant difference in mean WAB Scores between WVU $(\mathrm{m}=5.43, \mathrm{sd}=2.67)$ and NWU $(\mathrm{m}=6.27 \mathrm{sd}=1.84)$, while comparisons between the other universities were found to be non-significant. From this data, we could extrapolate that WVU and SU have relatively accessible websites compared to the inaccessible websites of NWU. 


\section{$\underline{\text { Table } 4.1 \text { and } 4.2}$}

Table 4.1. WAB Score Means of the 3

Universities

\begin{tabular}{lllll} 
University & Mean & $\mathrm{N}$ & Std. Deviation \\
WVU & 5.4261 & 94 & 2.67592 \\
\hline NWU & 6.2696 & 94 & 1.84295 \\
SU & 5.6295 & 94 & 2.02824 \\
Total & 5.7750 & 282 & 2.23273
\end{tabular}

Table 4.2. ANOVA

\begin{tabular}{l|l|l|l|l|l|} 
& $\begin{array}{l}\text { Sum of } \\
\text { Squares }\end{array}$ & df & Mean Square & F & Sig. \\
\hline $\begin{array}{l}\text { Between } \\
\text { Groups }\end{array}$ & 36.429 & 2 & 18.214 & 3.725 & .025 \\
\hline $\begin{array}{l}\text { Within } \\
\text { Groups }\end{array}$ & 1364.382 & 279 & 4.890 & & \\
Total & 1400.810 & 281 & & & \\
\hline
\end{tabular}




\section{Discussion: WVU websites}

WVU had the lowest WAB score mean among the three universities studied. The mean WAB score of $94 \mathrm{WVU}$ websites was 5.43. According to the WAB Score metric, a score above 5.5 makes a website inaccessible and a score below 5.5 would be accessible to an extent (see Figure 4.1), depending on the individual measurements of the 25 accessibility checkpoints used to calculate the score (see table 4 in appendixes). The mean WAB score of the WVU websites is very close to the inaccessible level. Individual WVU website WAB scores deviated greatly. The 94 websites that were analyzed had WAB Scores that ranged from 1 (almost perfectly accessible) to 11.95 (highly inaccessible). There are several examples of important WVU websites that have highly inaccessible scores. For instance, the Health Sciences Center Library website ( http://www.hsc.wvu.edu/library/) violated most of the 25 checkpoints and received a score of 11.4. The website could barely be accessed by any individual with a disability, including individuals with visual impairments because of major accessibility barriers. There were 16 image type links on the site that contained no alternative text (for an example see the top bar in image 4.1). When this website was accessed with JAWS 8.0 (a screen reader), only three plain text paragraphs and side bar links were distinguishable. 
Figures 4.1 and 4.2.

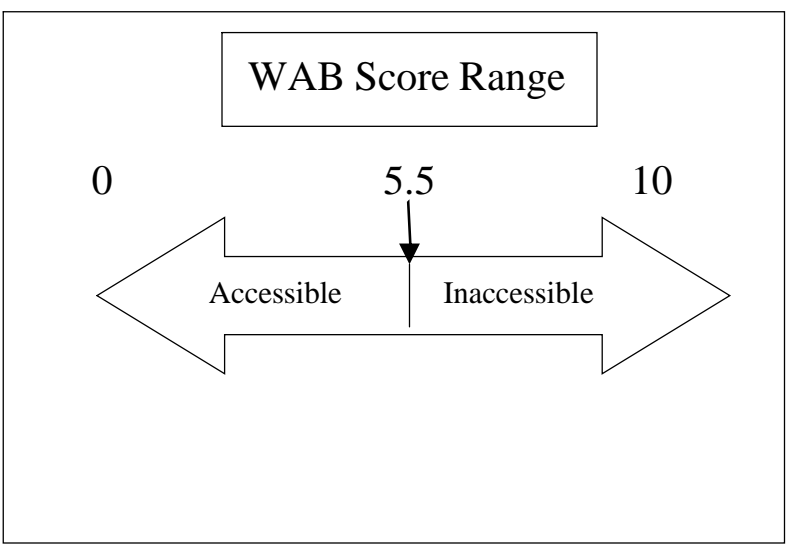

Figure 4.1. WAB Score Range

For ADA compliance, there must be some type of text separator

Bad Example:

Home Products Company

Good Example:

Home > Products > Company

Figure 4.2 Examples of Link Errors 


\section{Image 4.1 Health Sciences Library Website}

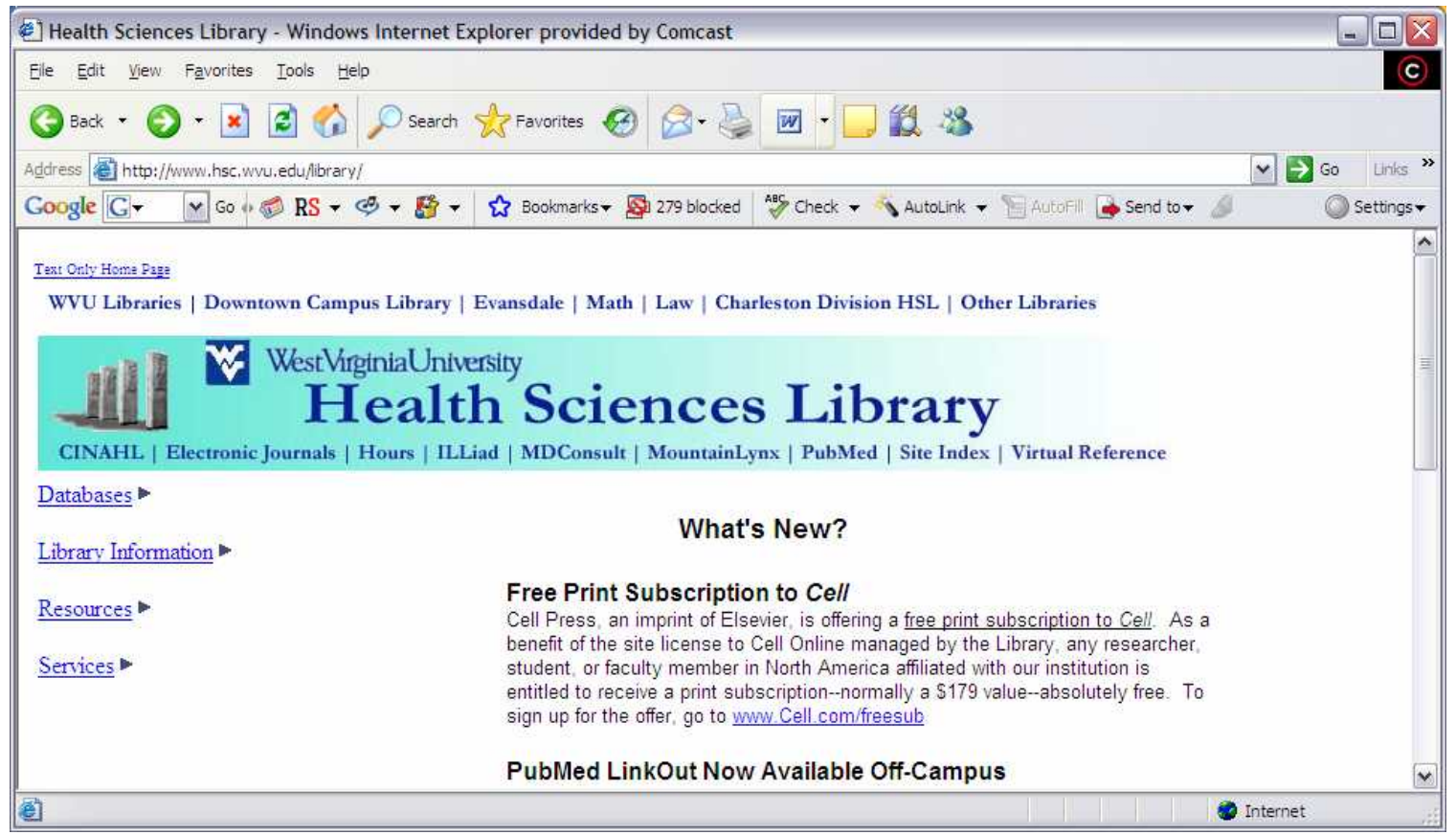


The software could not read the links without alternative text, therefore, an individual using JAWS to access this page would not even realize that the 16 links existed on the page. An individual accessing the site in this way would think that the page only consisted of the plain text and side bars. The site does contain a text-only link, but the link is in a tiny 7.5 font at the very top right of the page, an individual tabbing through the page or using a screen reader could easily miss it. When the text-only home page link is accessed, the text is in a small 10 point font, but the links are appropriately separated with more than white space. However, the text-only version of the web page does not contain all of the information provided on the main page and some links on the sites are missing or different from one to the other.

The WVU Future Students website ( http://www.wvu.edu/FutureStudents/) also violated several accessibility checkpoints including those specific to visual impairments. The site was scored at 10.7 (highly inaccessible) because of several accessibility barriers that were calculated. If a future student with a cognitive impairment or visual impairment were to visit the site, they would have a difficult time accessing most of the important WVU links on the site. Sixteen links listed across the bottom of the page are only separated by white space, a violation of ADA compliance (refer to the bad example in figure 4.2 and Image 4.2). Inspection of the HTML code of the website found that the links were separated by image code and could be read by a screen reader, but the appearance of the links on the page could be difficult for someone with visual or cognitive impairment to discern. Also, some links contain white text on a light blue background, a very low contrast option that could be difficult to see (See image 4.2). 


\section{Image 4.2 WVU Future Students Site}

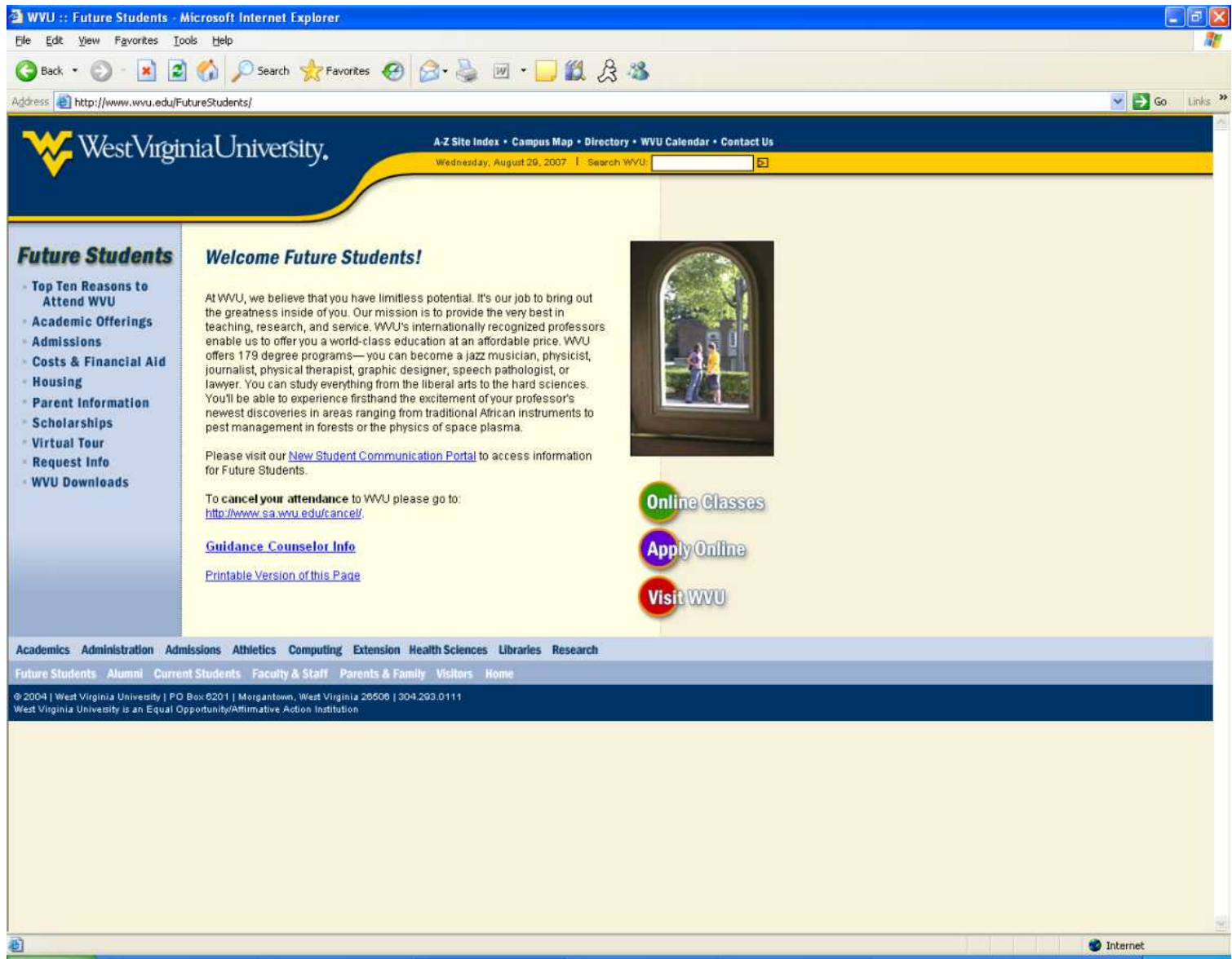


As mentioned earlier, some WVU websites were highly accessible. For instance, The Biometric Knowledge Center website ( http://bknc.wvu.edu/directions/) was almost completely accessible and received a score of 1 . It could easily be navigated with a screen reader like JAWS, unlike the Health Sciences Library website. The text on the site was well-spaced with a standard font, two characteristics that make the website more accessible because they make text easier to read for individuals with visual impairments. The only violations were two links that were separated only by white space (refer to figure 4.2 and Image 4.3) .As illustrated by these website examples, most of the WVU websites that had high WAB Scores had several checkpoint violations, with some in the high medium and low priority levels and the website with low scores had low priority checkpoint violations. 


\section{Image 4.3. Biometric Knowledge Center Website}

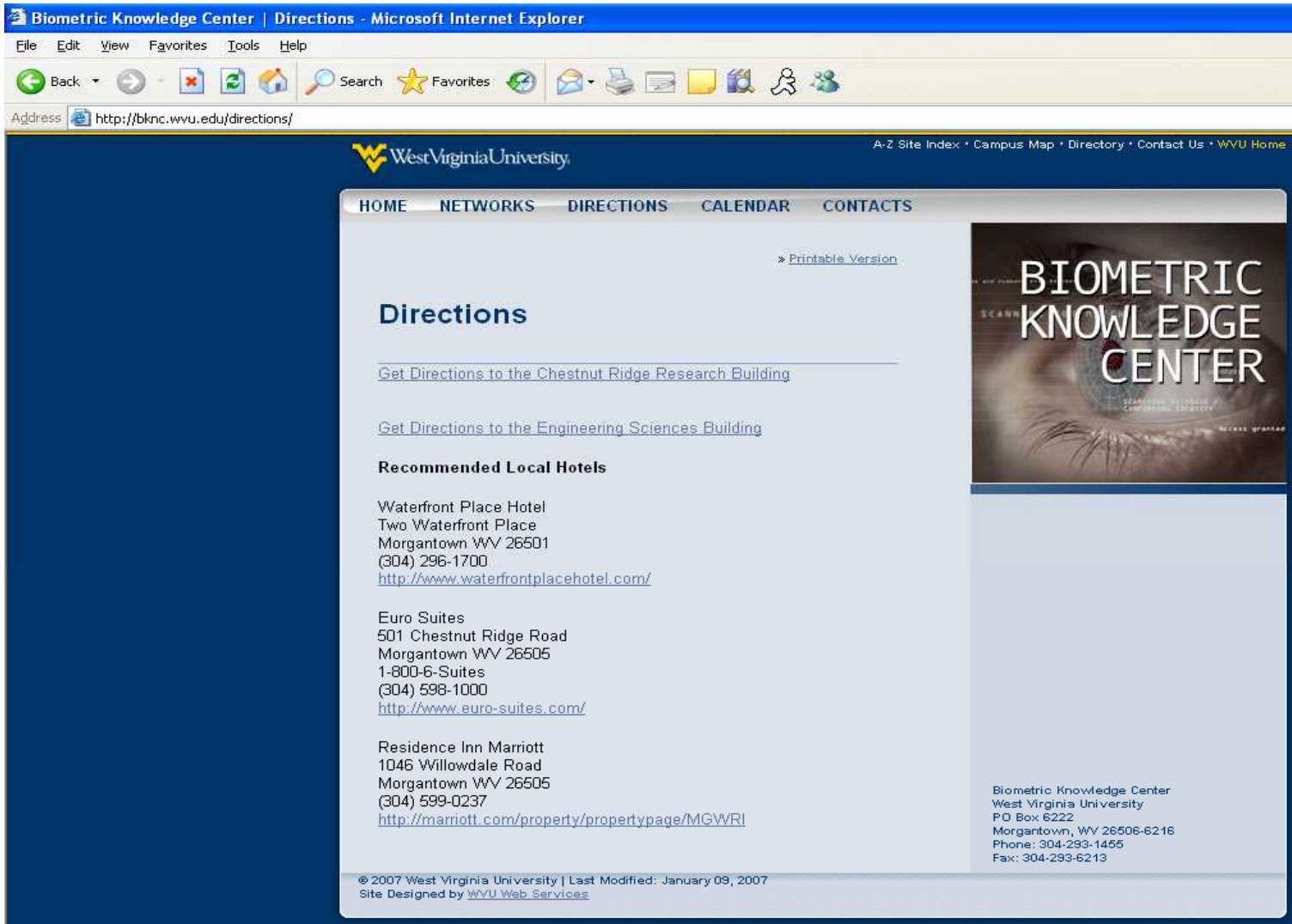




\section{Discussion: NWU websites}

NWU had the highest mean website WAB Score $(m=6.27)$ among the three universities studied and also had the lowest standard deviation between sites $(\mathrm{sd}=1.84)$. As mentioned earlier, a WAB Score of 5.5 or above is considered inaccessible.

According to the WAB measurement in this study, an average of NWU websites is inaccessible. The most inaccessible NWU website was a site that listed campus events which received a WAB Score of 9.37. There were some important prospective student websites that also scored on the inaccessible level. The NWU Future Student website was one of the most inaccessible sites (9.15). The website contained high priority checkpoint violations including those important to individuals with visual impairments like lack of alternative text, font size and ill defined links (See image 4.4). There are images of text on the site that have no alternative text for screen reading software to detect. A student with a visual impairment accessing the site would not even know that the text existed on the page. Another checkpoint that the site violates is the requirement of links to be self-explanatory. Several links on the Future student website contained simple phrases that might be misunderstood or misinterpreted by a user with a disability and could be very confusing to an individual using screen reading software. 


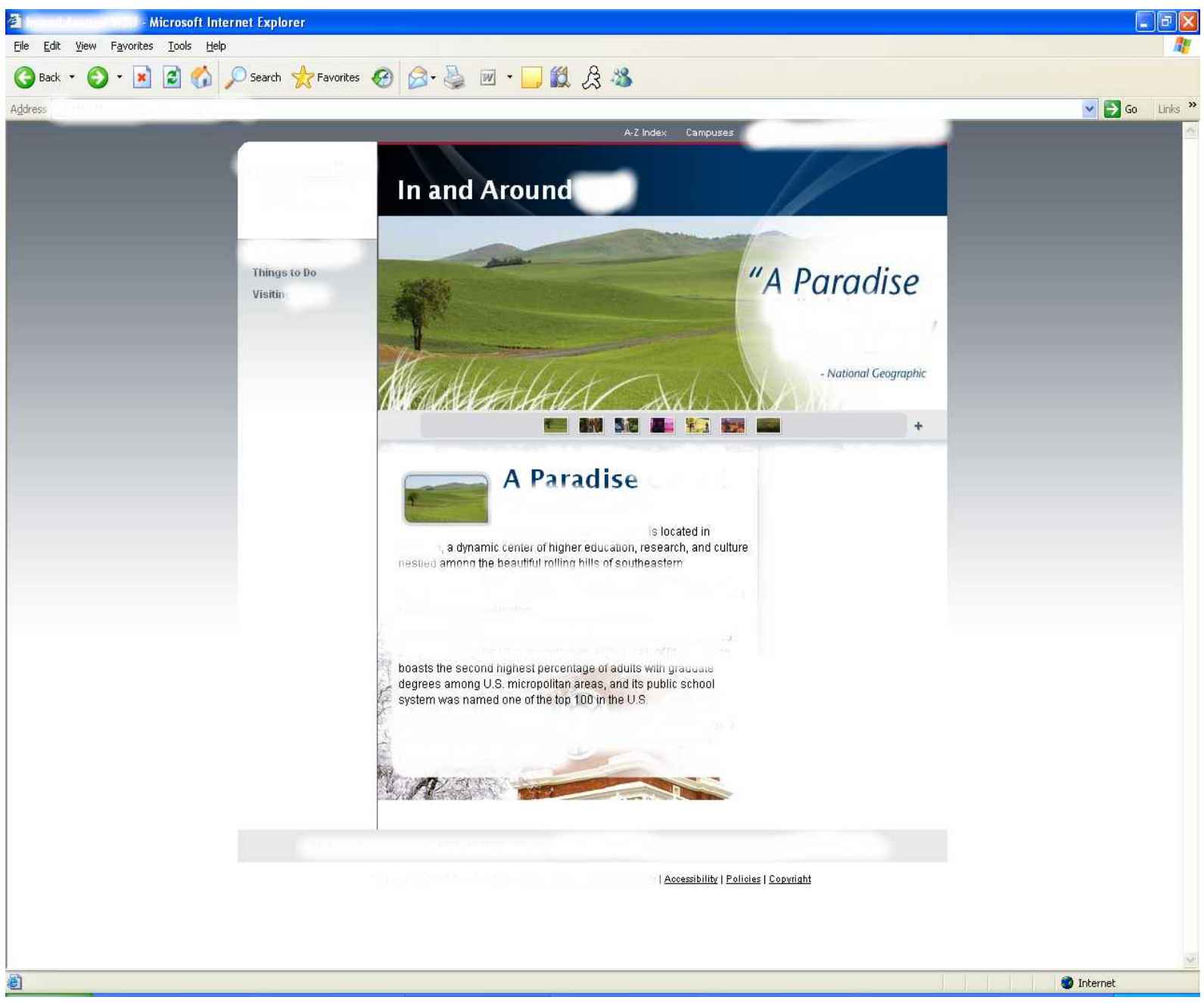


NWU also had some highly accessible websites including a website for speakers that received a WAB Score of 1 (see image 4.5), almost perfectly accessible. Unlike the Future Students website, the Speaker site had alternative text for all images and links were properly defined. According to the WAB Score, the Speaker website could easily be accessed by most individuals. These two websites illustrate the findings of the NWU data well. Like the Future Students site, a majority of the high scoring websites were inaccessible due to high priority accessibility barriers, accessibility errors that could potentially cause parts of a website or a whole website to be inaccessible to an individual with a disability. In contrast, sites that had very low WAB Scores had mainly low priority checkpoint violations, errors that might frustrate a user with a disability, but not cause them to be unable to access the information. 


\section{Image 4.5. NWU Visitors site}

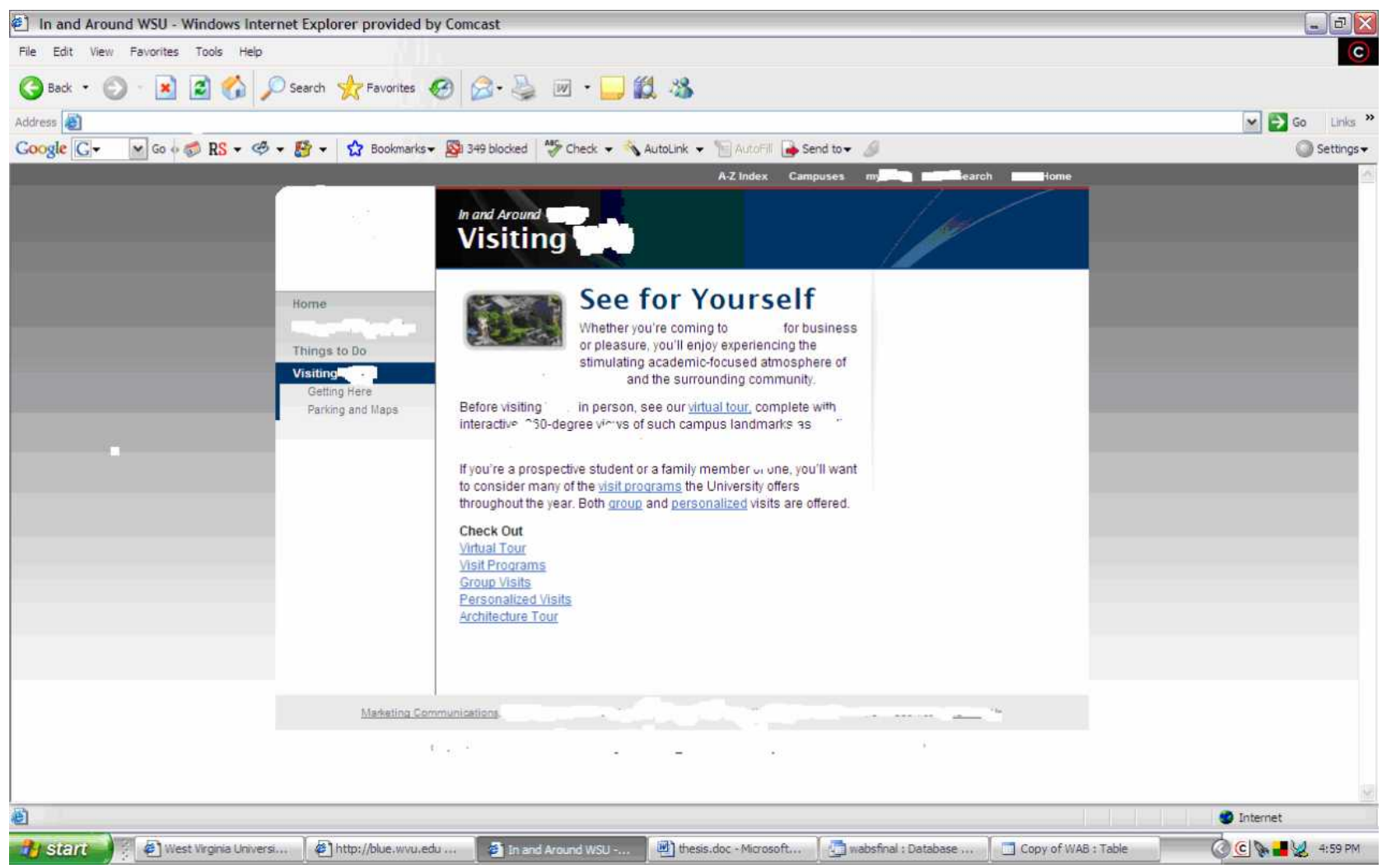




\section{Discussion: SU websites}

The mean WAB Score for SU websites was $5.63(\mathrm{sd}=2.03)$. Of the $94 \mathrm{SU}$ websites analyzed, the most inaccessible website received a WAB Score of 9.46. Unfortunately, the site that received this score was the university's main website. The SU main webpage had major side bar image links that lacked alternative text, including main school information links and popular links (See Image 4.6). There was a school news feature with several of the day's news stories that could not be read at all with a screen reader. A student using the software wouldn't even know that the news feature existed on the page. The website also has several images that are not labeled with alternative text and would be useless to an individual using a screen reader. The website text is a small nine point font and the user isn't given an opportunity to enlarge the text. Most of the text areas do not offer enough contrast or white space for a visually impaired individual to successfully access the site (See Image 4.6). 


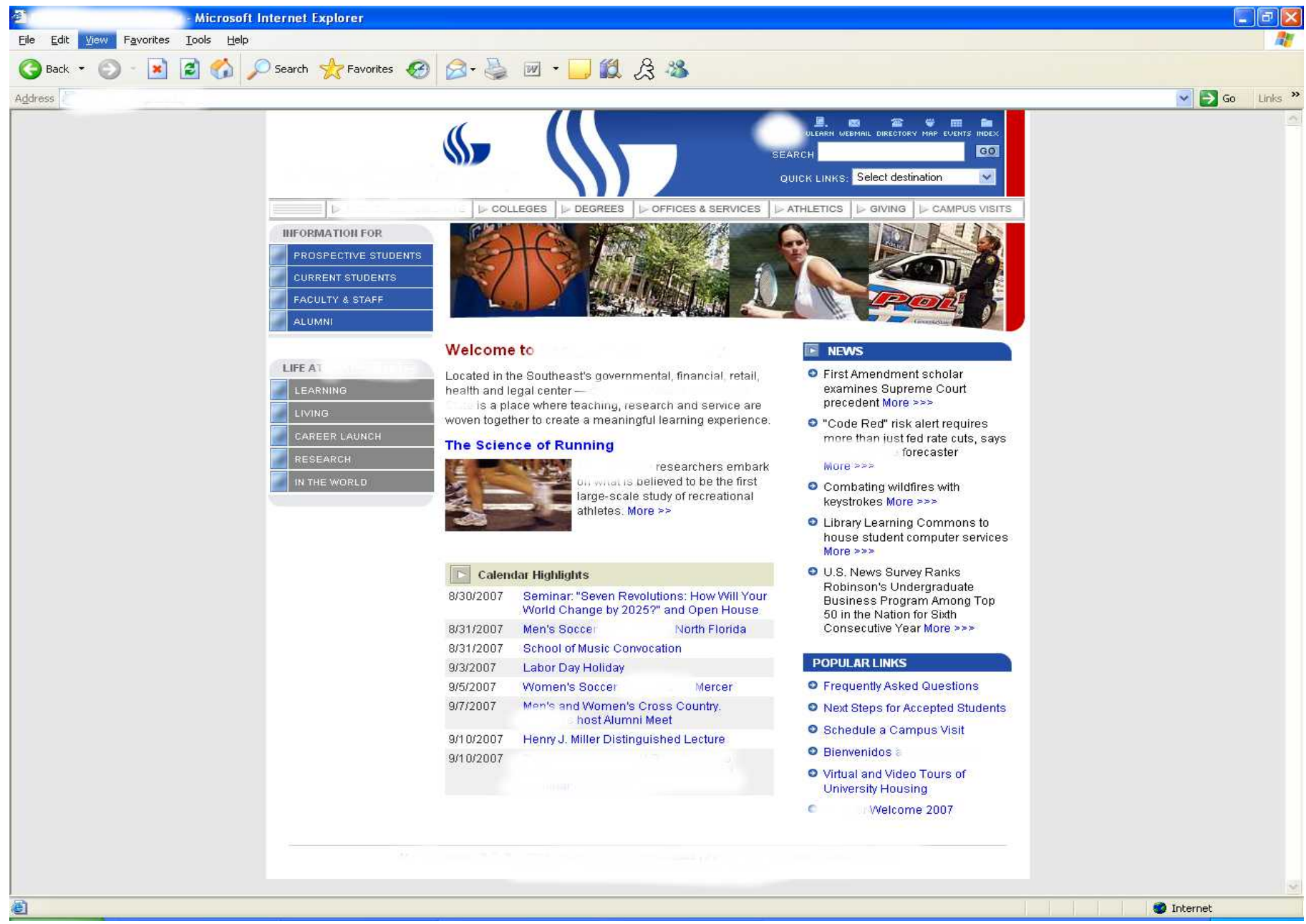


The most accessible website at SU, an overview of academic programs, received a WAB Score of 3 (see image 4.7). Unlike the main webpage, all of the links on this website were accessible. The only accessibility problems were three photos without alternative text and a header image that also lacked alternative text. Even though there were only a couple of mistakes, the site did not score lower because the mistakes that did exist were high priorities on the checkpoints list. The academics program website also had a high contrast color scheme and a larger 12 point font, both factors that enhance its accessibility for individuals with visual impairments. The analyses of SU website data follow the pattern of these two website examples. For instance, the websites with high WAB Scores, like the main web page, had violations of several high priority checkpoints, whereas, the websites with low WAB Scores also had high priority violations, only fewer. 


\section{Image 4.7. SU academics program site}

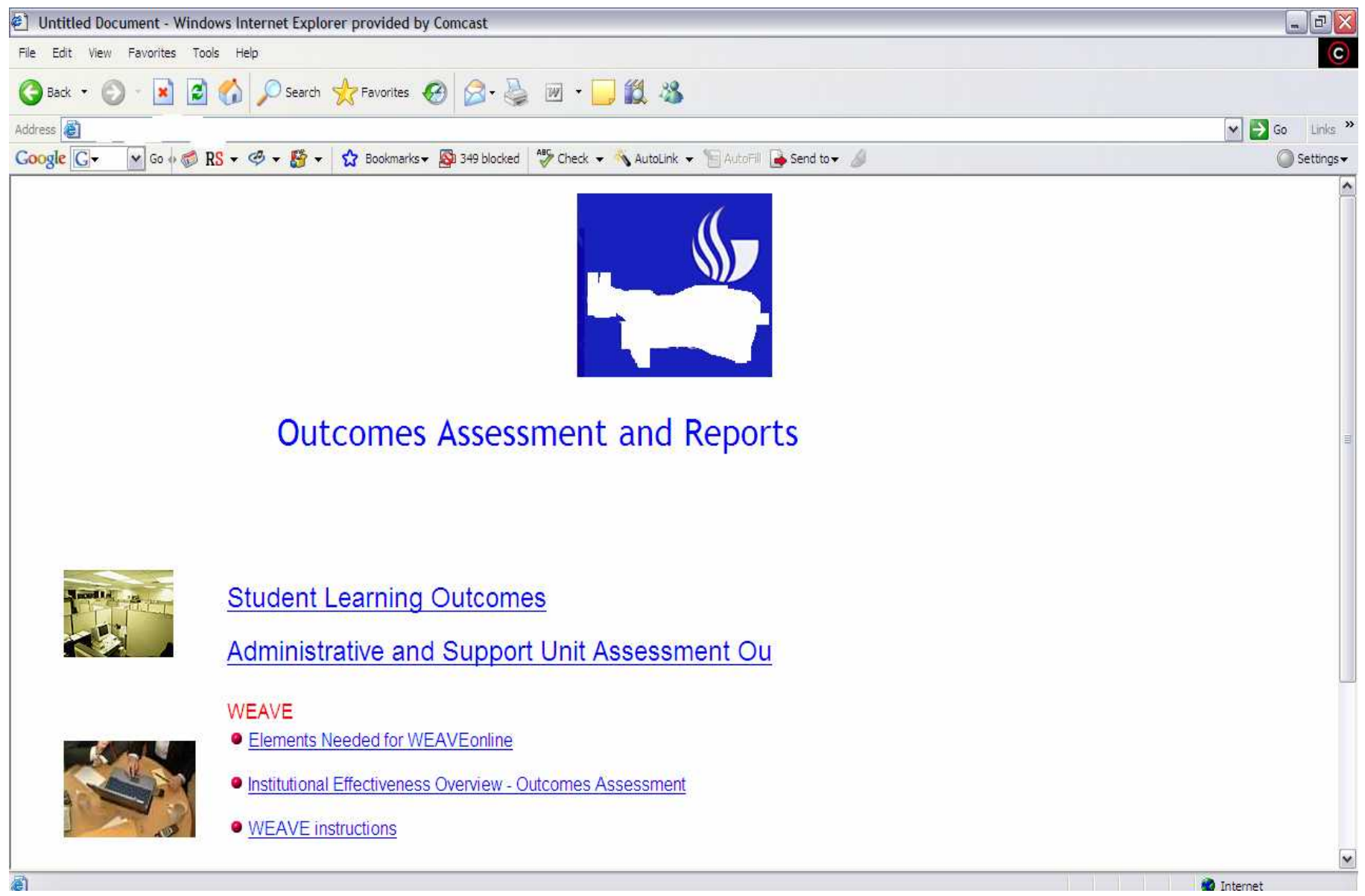




\section{Comparisons: WVU, NWU, SU}

Mean WAB score calculations showed that WVU had the lowest mean WAB score (5.43), the university in the South (SU) had the next to lowest (5.63) and the university in the Northwest (NWU) had the highest (6.27). However, WVU websites had the highest standard deviation (2.68) with WAB scores ranging from 1 to 11.95. This range is broad compared to that of the university in the Northwest (1-9.3) and the university in the South (3-9.4). According to Tukey's multiple analyses, WVU and NWU WAB Score means are significantly different, but the relationship between WVU and SU and NWU and SU are non-significant.

As described above, all three of the universities studied had major website accessibility barriers including high priority violations. Generally, WVU websites that had higher more inaccessible scores contained checkpoint violations in all three degrees of priority checkpoint levels. In contrast, NWU and SU websites that had high WAB Scores violated mostly high priority checkpoints. Also, WVU websites with more accessible scores contained mainly low priority mistakes, similar to the more accessible sites of NWU. However, the lower scoring websites at SU had high priority violations, only less than the more inaccessible sites.

\section{Conclusions}

This study is the first comprehensive study assessing the accessibility of WVU websites for individuals with disabilities, specifically individuals with visual impairments and comparing those results to those of comparable universities in other areas of the country. Compliance with specifications of website accessibility is an important goal for any state university and is also required by law. This study provides accurate and complete data that can be used to bring the studied university websites within accessibility compliance. For instance, WVU websites that were measured had a mean WAB Score that was accessible by .07 points (based on the WAB accessibility threshold of 5.5), but with further inspection it can be seen that specific sites and departments had severely inaccessible websites. 
The wide accessibility range of WVU websites (1-11.95) suggests that there are several different people in charge of designing the websites. It also shows that there is a lack of centralized guidance concerning website accessibility. Whereas, all three universities' websites had a number of violations that involved high priority checkpoints that were specifically important to individuals with visual impairments, the WVU websites had more significant barriers for individuals with visual impairments. The websites at WVU that were particularly inaccessible to individuals with visual impairments consisted of mostly major design elements and graphics. Basically everything that the designer might think made the website more appealing, also made the website less accessible.

These findings not only illustrate a problem with the current web accessibility strategy in place at the University, but they also offer a glimpse into correcting the problems that do exist. One could argue that the WVU pages that were more accessible were more basic and clean than the inaccessible sites, but design elements and catchy graphics do not have to be avoided in order to make websites accessible, simply adding an easily navigable site map would greatly improve the accessibility of some of WVU's worst sites. Because a few of the websites at the University had almost perfect accessibility; it would seem that the knowledge of accessibility procedures exists. It is this knowledge that needs to be applied to the websites that had WAB scores of 5.5 and above. Changes like these could easily be implemented by designing an all-encompassing website accessibility guidebook for all of the University's web designers to use and by creating a presentation outlining accessibility basics for all employees involved in website building. Annual training events could also be utilized to discuss advances in accessibility options and any changes in accessibility law. Centralizing accessibility oversight would be a simple proactive solution to solving a large problem before legal issues could present themselves.

As for correcting the existing accessibility problems, the high and low priority violations that were found on WVU websites are mostly items that would take little time to correct. For instance, adding alt tags to images, a high priority violation, can be fixed simply by adding an alt text tag and a description for the image. Even less involved, are the remedies for text size and contrast, these involve simply typing in a new font size or 
color code into the existing web code. These small solutions could be presented to current website designers at an accessibility specific training and outlined in the guidebook along with common mistakes and solutions. The accessibility scanning program used in this study pinpoints every small mistake on a given web page and would make it easy to go in and fix current inaccessible items. Methods used in this research do have the ability to make the accessibility process much simpler.

This research should serve as a model for any university to assess their current level of accessibility and to locate the specific areas of its websites that are particularly inaccessible. Future research could take a more qualitative approach and explore the knowledge web designers have about accessibility through one on one interviews and surveys. A future study might also concentrate on the idea of a link between "catchy", complex website design and inaccessibility. There are several avenues that could be explored to add to the findings of this research.

However, the results of this study do have limitations. Only 94 websites were assessed for each university, because of time and technological constraints. The WebCrawler program used froze up when assessing large amounts of URLs, requiring the need for a smaller sample size. Also, the WAB scores presented are only a snapshot of the websites at a specific time. Elements and areas addressed could have been modified during the study. Despite these limitations, it is clear that all three of the universities studied have definite accessibility barriers that need to be addressed. This study should serve as a comprehensive tool to accomplish the goal of website accessibility. 


\section{Bibliography}

American Foundation for the Blind. "Blindness Statistics". Available from http://www.afb.org/Section.asp?SectionID=15 ;accessed 17 January 2007

Assistive Technology Act of 1998, 105-394, S.2432. $105^{\text {th }}$ Congress. Second Session.

Disability Rights Commission. "The web: Access and Inclusion for Disabled People”, 2004. Available from www.drcgb.org/publicationsandreports/2.pdf; accessed 17 January 2007

Federici, Stefano et al. “Checking an Integrated Model of Web Accessibility and Usability evaluation for disabled people”. Disability and Rehabilitation (2005) Vol.27 Issue 13:781-790

Foley, A. and Regan, B., Best practices for web accessibility design and Implementation (2003). Available from http://macromedia.com/resources/education/whitepapers; accessed 11 February 2007.

Fujiki, Tadayoshi. “A Tool for Improving the Web Accessibility of Visually Handicapped Persons”. Journal ofMedical Systems. (2006) Vol. 30 Issue 2:8389

Hackett, Stephanie, Bambang Parmanto, and Xiaoming Zeng. “A retrospective Look at Website Accessibility over Time”. Behavior and Information Technology. (2005) Vol. 24 \#6:407-417 
Hackett, Stephanie and Bambang Parmanto. “A Longitudinal Evaluation of Accessibility: Higher Education Websites”. Internet Research. (2005)Vol.15 \#3: 281-294

HEATH Resource Center. "2001 College Freshmen with Disabilities: A Biennial Statistical Profile”. Washington, D.C.: American Council on Education, 2001.

Heim, Judy. “Locking Out the Disabled”. PC World. Sept.2000, 181-185.

How to Avoid Discrimination in Access to Online Education. Audio conference. CD-ROM. Thompson Interactive. www.thompsoninteractive.com. 2006.

Klein, David et al. "Electronic Doors to Education: Study of high School Accessibility in Iowa”. Behavioral Sciences and the Law. (2003) January: 2749

“Know your Users: Web Accessibility from the User's Perspective”. VHS. California State University. 26min. 37sec..2003

Miller, Ron. "Designing Sites with Accessibility in Mind” EContent. Jan./Feb.2006,21-24. www.econtentmag.com.

National Center for Accessible Media. “Accessible Digital Media: Design Guidelines for Electronic Publications, Multimedia and the Web”. Available at http://ncam.wgbh.org/publications/adm; accessed on 23 Feb.2007.

Nielsen, J., Designing Web Usability. Indianapolis, Indiana, US: New Riders Publishing, 2000. 
Robb, Drew. “One Site Fits All”. COMPUTERWORLD, 28 March 2005. www.computerworld.com.

Rowland, C., \& Smith, T. "Web Site Accessibility. The Power of Independence”(Summer Edition 1999), 1-2. Outreach Division, Center for Persons with Disabilities: Utah State University.

Schmetzke, A. (2000). Web Page Accessibility on University of Wisconsin Campuses. A Comparative Study. Unpublished study, University of Wisconsin.

Section 508. “508 Law”. Available at http://www.section508.gov/index.cfm?FuseAction=Content\&ID=3; acessed on 12 Jan. 2007

Sliwa, Carol. “Accessibility Issue comes to a Head: Target lawsuit could be a test case; new wave of apps concerns blind users”. COMPUTERWORLD. 8 May 2006. www.computerworld.com.

USDOJ , "Section 508 self-evaluation Webpage accessibility questionnaire for component web contacts” (2003). Available from www.usdoj.gov/crt/508/web.htm; accessed on 17 January 2007.

Walden, B., C. Rowland, and P. Bohman. "Year One Report: Learning Anytime Anywhere for Anyone". Unpublished report to the U.S. Department of Education, 2000.

Web Accessibility in Mind (WEBAIM). "United States Law: Overview of the Americans with Disabilities Act”. Available at http://www.webaim.org/articles/laws/usa/ada.php; accessed on 12 Jan. 2007. 
W3C.“Objects, Images and Applets”. 24 Dec. 1999. Available at http://www.w3.org/TR/html401/struct/objects.html\#adef-alt; accessed on 12 Feb. 2007

W3C. "Web content accessibility Guidelines 1.0". 5 May 1999. Available at http://www.w3.org/TR/WAI-WEBCONTENT/; accessed on 12 Fe. 2007

Zeng, $X$, "Evaluation and enhancement of web content accessibility for persons with disabilities”. Dissertation. 2004, University of Pittsburgh, Pittsburgh. Available from http://etd.library.pitt.edu/ETD/available/etd04192004-155229/unrestricted/XiaomingZeng_April2004.pdf; accessed on 2 Feb.2007 
Appendix

\section{Table 5.1: Checkpoint violations of WVU, NWU and SU}

\begin{tabular}{|c|c|c|c|c|}
\hline $\begin{array}{l}\text { WAI } \\
\text { Priority }\end{array}$ & Checkpoint & School & $\begin{array}{l}\text { Number of Potential } \\
\text { Violations }\end{array}$ & Number of violations \\
\hline \multirow{3}{*}{1} & \multirow{3}{*}{ Provide alternative text for all images. } & WVU & 2227 & 647 \\
\hline & & NWU & 2388 & 160 \\
\hline & & SU & 939 & 4 \\
\hline \multirow{3}{*}{1} & \multirow{3}{*}{ Provide alternative text for each APPLET. } & WVU & $\mathbf{0}$ & $\mathbf{0}$ \\
\hline & & NWU & $\mathbf{0}$ & $\mathbf{0}$ \\
\hline & & SU & $\mathbf{0}$ & $\mathbf{0}$ \\
\hline \multirow{3}{*}{1} & \multirow{3}{*}{ Provide alternative content for each OBJECT. } & WVU & 2 & 2 \\
\hline & & NWU & 7 & 7 \\
\hline & & SU & $\mathbf{0}$ & $\mathbf{0}$ \\
\hline \multirow{3}{*}{1} & \multirow{3}{*}{ Provide alternative text for all image-type buttons in forms. } & WVU & 5 & $\mathbf{0}$ \\
\hline & & NWU & $\mathbf{0}$ & $\mathbf{0}$ \\
\hline & & SU & 54 & $\mathbf{0}$ \\
\hline \multirow{3}{*}{1} & \multirow{3}{*}{ Provide alternative text for all image map hot-spots (AREAs). } & WVU & 120 & 23 \\
\hline & & NWU & 264 & 1 \\
\hline & & SU & $\mathbf{0}$ & $\mathbf{0}$ \\
\hline \multirow{3}{*}{1} & \multirow{3}{*}{ Each FRAME must reference an HTML file. } & WVU & $\mathbf{0}$ & $\mathbf{0}$ \\
\hline & & NWU & $\mathbf{0}$ & $\mathbf{0}$ \\
\hline & & SU & $\mathbf{0}$ & $\mathbf{0}$ \\
\hline \multirow{3}{*}{1} & \multirow{3}{*}{ Give each frame a title. } & WVU & $\mathbf{0}$ & $\mathbf{0}$ \\
\hline & & NWU & $\mathbf{0}$ & $\mathbf{0}$ \\
\hline & & SU & $\mathbf{0}$ & $\mathbf{0}$ \\
\hline \multirow{3}{*}{2} & \multirow{3}{*}{ Use a public text identifier in a DOCTYPE statement. } & WVU & 94 & 32 \\
\hline & & NWU & 94 & 27 \\
\hline & & SU & 94 & 18 \\
\hline \multirow{3}{*}{2} & \multirow{3}{*}{$\begin{array}{l}\text { Use relative sizing and positioning (\% values) rather than } \\
\text { absolute (pixels). }\end{array}$} & WVU & 4565 & 1266 \\
\hline & & NWU & 5190 & 2553 \\
\hline & & SU & 986 & 79 \\
\hline 2 & Nest headings properly. & WVU & 117 & 29 \\
\hline
\end{tabular}




\begin{tabular}{|c|c|c|c|c|}
\hline & & NWU & 123 & 16 \\
\hline & & SU & 334 & 132 \\
\hline & \multirow{3}{*}{ Provide a NOFRAMES section when using FRAMEs. } & WVU & $\mathbf{0}$ & $\mathbf{0}$ \\
\hline \multirow[t]{2}{*}{2} & & NWU & o & $\mathbf{0}$ \\
\hline & & SU & $\mathbf{0}$ & $\mathbf{0}$ \\
\hline \multirow{3}{*}{2} & \multirow{3}{*}{ Avoid blinking text created with the BLINK element. } & WVU & $\mathbf{0}$ & $\mathbf{0}$ \\
\hline & & NWU & $\mathbf{0}$ & $\mathbf{0}$ \\
\hline & & SU & $\mathbf{0}$ & $\mathbf{0}$ \\
\hline \multirow{3}{*}{2} & \multirow{3}{*}{ Avoid scrolling text created with the MARQUEE element. } & WVU & $\mathbf{0}$ & $\mathbf{0}$ \\
\hline & & NWU & 0 & 0 \\
\hline & & SU & 0 & $\mathbf{0}$ \\
\hline \multirow{3}{*}{2} & \multirow{3}{*}{ Do not cause a page to refresh automatically. } & WVU & $\mathbf{0}$ & $\mathbf{0}$ \\
\hline & & NWU & $\mathbf{0}$ & $\mathbf{0}$ \\
\hline & & SU & $\mathbf{0}$ & $\mathbf{0}$ \\
\hline \multirow{3}{*}{2} & \multirow{3}{*}{ Do not cause a page to redirect to a new URL. } & WVU & $\mathbf{0}$ & $\mathbf{0}$ \\
\hline & & NWU & $\mathbf{0}$ & $\mathbf{0}$ \\
\hline & & SU & $\mathbf{0}$ & $\mathbf{0}$ \\
\hline \multirow{3}{*}{2} & \multirow{3}{*}{ Make sure event handlers do not require use of a mouse. } & WVU & 303 & 303 \\
\hline & & NWU & 656 & 656 \\
\hline & & SU & 789 & 789 \\
\hline \multirow{3}{*}{2} & \multirow{3}{*}{$\begin{array}{l}\text { Explicitly associate form controls and their labels with the } \\
\text { LABEL element. }\end{array}$} & WVU & 178 & 170 \\
\hline & & NWU & 9 & 8 \\
\hline & & SU & 117 & 117 \\
\hline \multirow{3}{*}{2} & \multirow{3}{*}{ Create link phrases that make sense when read out of context. } & WVU & 3612 & 3 \\
\hline & & NWU & 2255 & 1 \\
\hline & & SU & 3228 & 22 \\
\hline \multirow{3}{*}{2} & \multirow{3}{*}{$\begin{array}{l}\text { Do not use the same link phrase more than once when the links } \\
\text { point to different URLs. }\end{array}$} & WVU & 3612 & 75 \\
\hline & & NWU & 2255 & 77 \\
\hline & & SU & 3228 & 231 \\
\hline 2 & Include a document TITLE. & WVU & 94 & 3 \\
\hline
\end{tabular}




\begin{tabular}{|c|c|c|c|c|}
\hline & & NWU & 94 & 0 \\
\hline & & SU & 94 & 18 \\
\hline & \multirow{3}{*}{$\begin{array}{l}\text { Client-side image map contains a link not presented elsewhere } \\
\text { on the page. }\end{array}$} & WVU & 120 & 91 \\
\hline \multirow[t]{2}{*}{3} & & NWU & 264 & 240 \\
\hline & & SU & $\mathbf{0}$ & $\mathbf{0}$ \\
\hline \multirow{3}{*}{3} & \multirow{3}{*}{ Identify the language of the text. } & WVU & 88 & 60 \\
\hline & & NWU & 94 & 94 \\
\hline & & SU & 76 & 76 \\
\hline \multirow{3}{*}{3} & \multirow{3}{*}{ Provide a summary for tables. } & WVU & 496 & 496 \\
\hline & & NWU & 561 & 561 \\
\hline & & SU & 24 & 16 \\
\hline \multirow{3}{*}{3} & \multirow{3}{*}{$\begin{array}{l}\text { Include default, place-holding characters in edit boxes and text } \\
\text { areas. }\end{array}$} & WVU & 178 & 172 \\
\hline & & NWU & 9 & 7 \\
\hline & & SU & 117 & 60 \\
\hline \multirow{3}{*}{3} & \multirow{3}{*}{ Separate adjacent links with more than white } & WVU & 3612 & 506 \\
\hline & & NWU & 2255 & 107 \\
\hline & & SU & 3228 & 778 \\
\hline
\end{tabular}




\section{Sarah Jacobin}

sjacobin@mix.wvu.edu

\section{Education}

Master of Science, Journalism

December 2007

\section{WVU, Morgantown}

- Major: Journalism with a concentration in PR

- Minor: Disability studies

\section{Education}

\section{Bachelor of Science, Journalism}

\section{WVU, Morgantown}

Summa Cum laude

- Major: Journalism-news editorial

- Minor: American politics and policy

\section{Work History}

October 2005-

WVU Center for Excellence in Disabilities

present

959 Hartman Run Rd.

Morgantown, WV, 26505

Supervisor: Jeanne Grimm, Assistant Director

293-4692

May 2005-August

The Dominion Post 


\section{Skills/Abilities Journalism/Public Relations}

- Created published materials for a federally funded agency including brochures, information briefs, newsletters and fact sheets

- Worked with assistant director to write grants to secure government and private funding from major sources including HUD and the Assistive Technology Alliance (ATA)

- Developed public relations campaign for non-profits

- Wrote for two major West Virginia newspapers: The Dominion Post, The Charleston Gazette/Daily Mail

- Interned with KDKA television while obtaining B.S.

\section{Leadership}

- Supervised and assigned tasks to graduate assistants and student workers

- Provided software trainings and quick start guides to employees

- Trained employers, professionals and individuals on assistive technology and individuals with disabilities

\section{Communication}

- Wrote press releases

- Developed program materials including fundraising materials

- Dealt with contractors and employees statewide

- Provided information and referral to professionals and individuals statewide

- Provided technical assistance to state agencies 